Article

\title{
When Does Abusive Supervision Foster Ineffectual and Defensive Silence? Employee Self-Efficacy and Fear as Contingencies
}

\author{
Alisher Tohirovich Dedahanov ${ }^{1}$, Odiljon Sobirovich Abdurazzakov ${ }^{1, *}$, Abdulkhamid Komil ugli Fayzullaev ${ }^{2}$ (D) \\ and Wei Sun ${ }^{3}$ \\ 1 School of Business, Akfa University, Tashkent 100084, Uzbekistan; a.dedahanov@akfauniversity.org \\ 2 School of Business, Yeungnam University, Gyeongsan 38541, Korea; fayzziyo@gmail.com \\ 3 School of Economics, Anyang Normal University, Anyang 455000, China; popupoler@hotmail.com \\ * Correspondence: o.abdurazzakov@akfauniversity.org
}

\section{check for}

updates

Citation: Dedahanov, A.T.;

Abdurazzakov, O.S.; Fayzullaev,

A.K.u.; Sun, W. When Does Abusive

Supervision Foster Ineffectual and

Defensive Silence? Employee

Self-Efficacy and Fear as

Contingencies. Sustainability 2022, 14,

231. https://doi.org/10.3390/

su14010231

Academic Editors: Seung-Wan Kang,

Seung Yeon Son and Eunmi Jang

Received: 22 November 2021

Accepted: 23 December 2021

Published: 27 December 2021

Publisher's Note: MDPI stays neutral with regard to jurisdictional claims in published maps and institutional affiliations.

Copyright: (c) 2021 by the authors. Licensee MDPI, Basel, Switzerland. This article is an open access article distributed under the terms and conditions of the Creative Commons Attribution (CC BY) license (https:/ / creativecommons.org/licenses/by/ $4.0 /)$.

\begin{abstract}
This study investigates the relationships between abusive supervision and two forms of silence, ineffectual and defensive; the moderating role of self-efficacy in the association between abusive supervision and ineffectual silence and the contingency role of fear in the relationship between abusive supervision and defensive silence. We collected data from 685 employees in manufacturing companies. Of these, 271 were incomplete questionnaires and were excluded from the study; the remaining 414 responses were assessed in the analyses. The results indicate that abusive supervision fosters ineffectual and defensive silence. Moreover, the results suggest that even if supervisors are abusive, individuals with a higher level of self-efficacy tend to have a lower level of ineffectual silence. Furthermore, fear strengthens the link between abusive supervision and defensive silence. According to our knowledge, this work is the first to investigate the relationship between abusive supervision and ineffectual silence, the contingency role of self-efficacy in the link between abusive supervision and ineffectual silence and the moderating role of fear in the relationship between abusive supervision and defensive silence.
\end{abstract}

Keywords: abusive supervision; ineffectual silence; defensive silence; self-efficacy; fear

\section{Introduction}

Employees are regarded as valuable sources of ideas and information because their voices help the organization correct problems and make improvements [1]. When employees withhold information, their supervisors may not be aware of existing problems [2]; therefore, silence can cause accidents and corruption [3]. Moreover, silence can negatively influence decision making by blocking a variety of opinions and views. Hence, to benefit from the variety of employees' opinions and to reduce accidents and corruption in organizations, it is important to understand the factors that foster employee silence.

Supervision style plays a critical role in generating silence. Specifically, abusive supervision has a significant role in inducing employee silence [4]. Previous research has investigated the association between abusive supervision and employee silence and reported that the abusive behavior of supervisors fosters employee silence [5,6]. Despite the extensive research on abusive supervision and silence, two important questions remain unanswered and need to be addressed.

First, not all individuals react to abusive supervisors in the same way. That is, individuals can respond differently to the abusive behavior of supervisors [7]. Hence, previous studies $[7,8]$ suggest that research has yet to investigate the factors that impact individuals response to abusive supervision. Under abusive supervision, individuals may withhold information for different reasons. For example, individuals may practice ineffectual silence, remaining silent based on the belief that sharing information does not make a change in the workplace and that speaking up is futile [9] because of unfair treatment [10] by abusive 
supervisors. Employees who fear superiors' negative reactions to sharing information may remain silent to protect themselves [11] by practicing defensive silence. One stream of previous research [4] on abusive supervision and silence focused on the unitary construct of silence that involves the frequency and tendency of sharing ideas rather than individuals' intentions in withholding opinions. Another stream of research $[5,6]$ investigated the links between abusive supervision and one of the dimensions of the silence, defensive silence. Despite existing research [4-6,12-21], there is still a lack of understanding on the role of abusive supervision in inducing ineffectual silence, which is related to refraining from information sharing based on the perception that speaking up does not make a difference.

Second, according to Chi and Liang [22], individuals' response to abusive supervision varies based on their capabilities to handle the negative experiences that are triggered by supervisors. Thus, when supervisors are abusive, based on personal traits and beliefs, employees' level of silence may differ.

Even though several studies examined the link between abusive supervision and silence, very little is known about when employees remain silent and when they do not under abusive supervisors. The biopsychological theory of personality [23] explains the reactions of individuals to the external environment. According to the principles of this theory, when individuals expect rewards, individuals use approach behavior. In contrast, when individuals expect a threat or punishment, they use avoidance behavior. Individuals with a higher level of work-related self-efficacy that is defined as a confidence in one's capability to complete specific tasks successfully in certain circumstances [24,25] tend to perceive successfully accomplished tasks as achievements and rewards and therefore, are more likely to engage in approach behavior by sharing their ideas on work-related issues to improve the organization based on their self-confidence. Hence, we believe that despite abusive supervision, individuals with a higher level of self-efficacy tend to have a lower level of ineffectual silence because of their self-confidence in performing tasks successfully. On the other hand, fearful individuals are more likely to expect threat and punishment from the environment. Therefore, we believe that fearful individuals tend to use avoidance behavior by engaging in defensive silence to minimize undesirable outcomes under abusive supervision. Thus, we assume that fear strengthens the link between abusive supervision and defensive silence. Hence, in this study we use the biopsychological theory of personality as a framework to investigate the contingency roles of self-efficacy and fear on the link between abusive supervision and employee silence.

Despite the number of studies on abusive supervision and silence $[5,6,18]$ very little is known about the self-efficacy as a potential boundary condition that may impact the association between abusive supervision and ineffectual silence and the contingent role of fear between abusive supervision and defensive silence. For example, since there is still limited knowledge on the role of abusive supervision in fostering ineffectual silence, the role of self-efficacy in acting as a boundary condition on these two factors has not been examined. Moreover, as noted earlier, previous research [5,6] contributed to the literature by investigating the association between abusive supervision and defensive silence that is related to self-protection motives. However, these researchers did not investigate fear as a boundary condition between these two constructs.

Hence, to address these research gaps in the field, this research intends to study the links between abusive supervision and two forms of silence, ineffectual and defensive, examine the contingent role of self-efficacy in the link between abusive supervision and ineffectual silence and study the contingent effect of fear in the association between abusive supervision and defensive silence. Thus, our research attempts to extend the literature by providing new knowledge on individual factors that can foster or reduce the impact of abusive supervision on employee silence.

Investigating the associations between abusive supervision and these two forms of silence (i.e., ineffectual and defensive silence) enables the management of organizations to understand the motives and intentions of individuals in remaining silent when they suffer from the abusive behavior of supervisors. It is critical to understand this dynamic 
because it provides richer insight to give better recommendations to practitioners. Moreover, examining the boundary condition roles of self-efficacy and fear between abusive supervision and different forms of silence provides knowledge about when individuals withhold information and when they speak up under abusive supervision.

\section{Literature Review}

Employee Silence

There are unitary and multidimensional constructs of silence. The unitary construct of silence assesses the frequency and tendency of information sharing, whereas the multidimensional construct of silence evaluates the intentions of individuals in remaining silent [26]. According to Brinsfield [27], to have comprehensive knowledge about silence, it is not sufficient to assess the unitary construct of silence because silence behavior itself does not express the intention to remain silent. Hence, previous studies suggested a multidimensional construct of silence that explains individuals' motives to remain silent $[10,11,27]$. Pinder and Harlos [10] introduced two forms of silence, acquiescent and quiescent. Van Dyne et al. [11] continued Pinder and Harlos's study by offering the concepts of acquiescent, prosocial and defensive silence. Brinsfield [27] also contributed to the field by defining six forms of silence: ineffectual, defensive, deviant, acquiescent, relational, diffident and disengaged silence. Ineffectual silence is related to refraining from speaking up based on the belief that sharing opinions and suggestions does not change a situation in organizations; defensive silence is defined as concealing information, ideas and opinions based on fear and self-protection.

Abusive supervisors might discourage employees from speaking up by treating them unfairly [18], which consequently leads individuals to perceive that speaking up to make change in the organization is useless. Moreover, individuals tend to respond to abusive supervisors with defensive behaviors [5]. Therefore, in our study, we focus on ineffectual and defensive silence as the consequences of abusive supervision.

A number of empirical studies also investigates the associations between abusive supervision and employee silence. For example, Jain et al. [12] investigated the associations between abusive supervision, emotional intelligence and fear-based silence. Wang et al. [13] studied the mediating role of silence on the link between abusive supervision and employee work engagement. These authors reported that abusive supervision mitigates individual's work engagement via employee silence. Al-Hawari et al. [14] examined the mediating role of employee silence on the link between abusive supervision in employee's capacity to satisfy customers. According to Al-Hawari et al. [14], abusive supervision fosters employee silence which in turn mitigates employee's capacity to satisfy customers. Ai-Hua et al. [15] assessed the links between abusive supervision and employee silence via organizational politics. Park et al., [4] examined the mediating role of psychological distress on the relationship between abusive supervision and employee silence. According to Park et al. [4], abusive supervision fosters psychological distress which in turn reduces employees' tendency to share their concerns on work-related issues. Wang and Jiang [18] evaluated interactional justice as a critical mechanism on the link between abusive supervision and employee silence. Pangestu and Wulansari [20] studied the relationship between abusive supervision and employee silence via emotional exhaustion and organizational justice. As mentioned, despite the fact that a number of studies investigated the link between abusive supervision and employee silence, still we have a lack of understanding on the role of abusive supervision in fostering ineffectual silence and the situations in which abusive supervision triggers employee silence namely, ineffectual and defensive.

\section{Theory and Hypotheses}

\subsection{Abusive Supervision and Ineffectual Silence}

When abusive supervisors ridicule, yell and scream and humiliate employees, employees feel that they are being treated unfairly [28]. This unfair treatment is related to reduced voice and employee silence [29]. In unjust environments, employees become reluctant to 
share their work-related concerns [30]. Pinder and Harlos [10] stated that when individuals experience injustice and believe that their opinions are not considered seriously, they tend to withhold ideas by refraining from information sharing. According to Whiteside and Barclay [31], experiencing interactional justice gives individuals the perception that they can make a difference and meaningful change in their workplace. Hence, experiencing unfair treatment under abusive supervision triggers the perception that individuals cannot make a change or difference in the organization by sharing their suggestions and ideas. Therefore, we believe that when individuals are not treated with kindness, consideration, dignity and respect and their personal needs are overlooked by abusive superiors, they tend to refrain from information sharing by engaging in ineffectual silence based on the belief that shared work-related concerns are not taken seriously by management and that speaking up does not make a change. Thus, we assume that abusive supervision fosters ineffectual silence and suggest the following hypothesis:

Hypothesis 1 (H1). Abusive supervision is positively related to ineffectual silence.

\subsection{Moderating Role of Self-Efficacy}

According to the perspective of the biopsychological theory of personality [23], two brain-based systems, the behavioral inhibition system and the behavioral activation system, manage individuals' interactions with their environment. The behavioral inhibition system is associated with avoidance behavior, and the behavioral activation system is related to approach behavior. Signals of reward stimulate approach-type behavior, whereas signals of punishment and threat activate avoidance behavior.

Self-efficacy reflects individuals' confidence in organizing and executing actions to accomplish a certain behavior when they encounter difficulties [32]. Hence, Walumba et al. [33] indicated that people with a higher level of self-efficacy believe that they have the capability to accomplish tasks successfully and therefore, perceive that their recommendations can be seriously considered by management. We perceive that individuals with high self-efficacy tend to perceive the successful completion of tasks as an achievement and reward that stimulates their approach behavior. Therefore, people who have high self-efficacy tend to use approach behavior to achieve their goals by sharing their work-related concerns based on their self-confidence.

Thus, even though abusive supervisors mistreat employees and give the perception of unfairness, individuals with a higher level of self-efficacy still share their work-related concerns based on the perception that they can influence the environment and can make a change in the workplace. In contrast, under abusive supervision, individuals with a lower level of self-efficacy might be reluctant to express their suggestions and recommendations based on the belief that they are incapable of making a difference in the organization by practicing ineffectual silence. Hence, we believe that the higher the self-efficacy, the lower ineffectual silence will be under abusive supervision and suggest the following hypothesis:

Hypothesis 2 (H2). Self-efficacy moderates the relationship between abusive supervision perceptions and ineffectual silence, such that the positive link will be weaker for employees who have higher level of self-efficacy.

\subsection{Abusive Supervision and Defensive Silence}

Individuals receive high signals of threat from abusive supervision [5]. When individuals face external threats and confront stressors, they attempt to defend themselves [34] by using avoidance behavior. Thus, experiencing the abusive behavior of superiors motivates individuals to avoid threat-inducing stimuli. Previous research [5] has indicated that abusive supervisors pose a threat that leads subordinates to use avoidance and self-protection. We believe that one of the possible mechanisms of protection is defensive silence [35] because before individuals speak up, they calculate the benefits and costs of sharing information. When individuals perceive that speaking up is not safe and triggers threat and problems, they tend to protect themselves by refraining from information sharing [36] 
because they may fear losing promotion opportunities, compensation or employment [35]. Similarly, Brinsfield [27] stated that defensive silence is especially used as a response to external threats that are related to fear. Therefore, we believe that when supervisors are rude and abusive, individuals withhold relevant information due to self-protection. Hence, we suggest the following hypothesis:

Hypothesis 3 (H3). Abusive supervision is positively related to defensive silence.

\subsection{Moderating Role of Fear}

We believe that not all individuals who suffer from the abusive behavior of supervisors respond to abusive supervision with defensive silence. Individuals with fear are more likely to use avoidance and self-protection approaches [5]. That is, fearful individuals tend to expect punishment, threat or undesirable outcomes from the environment based on their susceptibility to external threats; therefore, these individuals attempt to use avoidance behavior to minimize threat and punishment.

Defensive silence is a fear-based coping mechanism that leads individuals to refrain from information sharing based on self-protection [27]. Hence, fear increases individuals desire to engage in defensive silence. Similarly, Guo et al. [35] indicated that fearful individuals try to neutralize a negative circumstance and to restore their well-being with defensive silence. Therefore, we believe that fearful individuals are more likely to refrain from information sharing based on self-defense and protection compared to individuals with a lower level of fear. In other words, the higher the fear level, the more defensive silence will occur among individuals with abusive supervision. Hence, based on the discussion above, we suggest the following hypothesis (Figure 1):

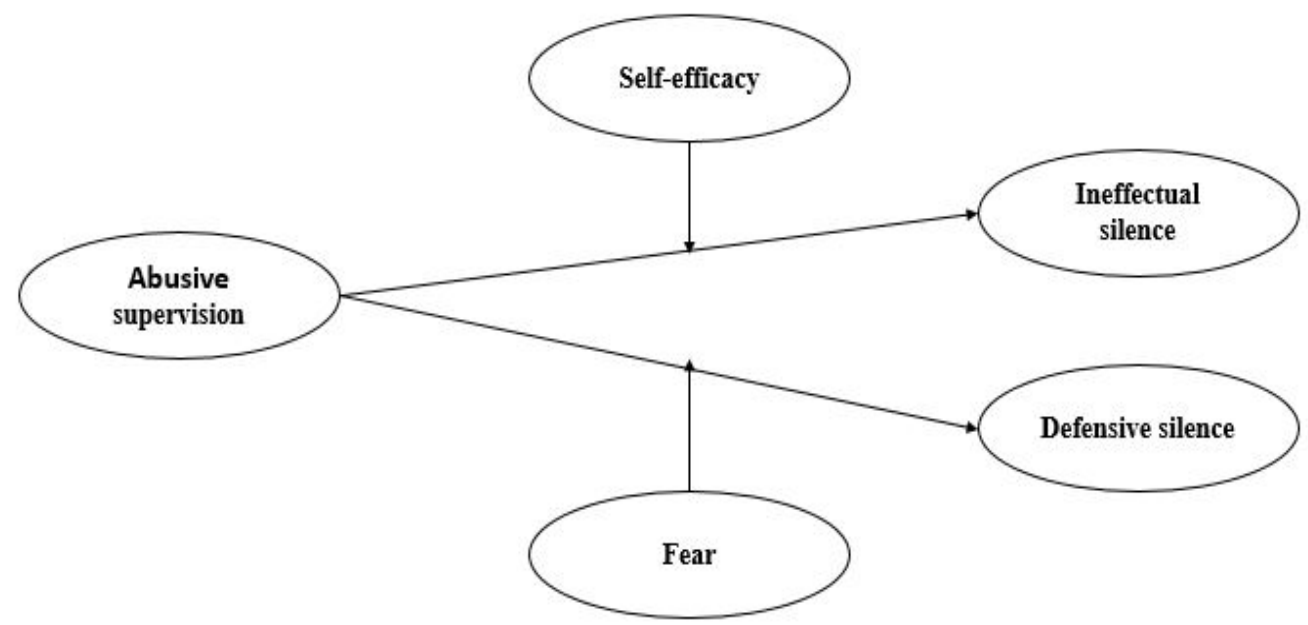

Figure 1. Hypothesized research model.

Hypothesis 4 (H4). Fear moderates the relationship between abusive supervision and defensive silence such that the positive link will be stronger for employees more inclined to fear.

\section{Methods}

A survey was conducted among 685 highly-skilled full-time employees of 21 manufacturing companies in the Republic of Korea. To collect data, we contacted with the management of organizations and explained the purpose of our study. Human resource department provided employee lists and we randomly selected respondents in each organization.

Paper-and-pencil survey was conducted in small group sessions in each company. We informed the respondents that participating in the survey was voluntary and provided verbal and written assurance of the confidentiality of responses by indicating that responses would be accessible only to research team. Moreover, to ensure the confidentiality of responses, participants were not asked to indicate themselves on the questionnaire. Between 
measures we applied a time lag (Time 1: August 2019; Time 2: October 2019). We coded each survey form with a researcher-assigned identification number and this identification number was informed to the respondents to match their answers in the second phase of data collection. At Time 1, abusive supervision and self-efficacy measures were collected, and at Time 2, fear, ineffectual and defensive silence measures were collected. This time lag mitigates the concerns over temporal causality that is confronted with cross-sectional study. Among the 685 responses, due to incomplete data we excluded 271 responses; thus, we received 414 usable questionnaires. The overall response rate was 60.4 percent. Of the 414 respondents, 40.6 percent were female and 59.4 percent were male. With respect to age, 18.8 percent were between 25 and 35 years, 43.5 percent were between 36 and 45 years, 32.4 percent were between 46 and 55 years, and 5.3 percent were between 56 and 65 years. Regarding education level, 61.4 percent of participants had a bachelor's degree; 33.8 percent had a master's degree and 4.8 percent had $\mathrm{PhD}$ degree.

\subsection{Measures}

The original questionnaires were developed in the English language; therefore, professional translators translated the questionnaire from English into the Korean language. We followed Brislin's [9] suggestion by back translating the items into English to confirm the appropriateness of translation. In this study, we rated all scale items on a five-point Likert scale ranging from 1-strongly disagree to 5-strongly agree. To evaluate fear, we used a scale of 1-very slightly to 5-extremely.

To measure abusive supervision, 13 items were adapted from Tepper [28]. The factor loadings of two items (Abusive 8 and Abusive 13) were less than 0.5. According to Russel [37], 0.5 is used as a cutoff for factor loadings. Hence, factor loadings lower than 0.5 were excluded from this study. Cronbach's $\alpha$ coefficient for this scale was 0.846 .

To evaluate silence, we adapted scales for ineffectual and defensive silence from Brinsfield's [27] study. The Cronbach's $\alpha$ for the ineffectual and defensive silence scales were 0.954 and 0.847 , respectively.

Self-efficacy was evaluated using items from Spreitzer's [38] study. Cronbach's $\alpha$ coefficient for this scale was 0.921 .

To assess fear, we derived items from Watson and Clark's [39] study. Employees indicated the extent to which they experienced fear in relation to their immediate supervisor. The scale's $\alpha$ reliability was 0.958 .

\subsection{Control Variables}

Previous studies $[40,41]$ controlled the gender, age, work experience and education level of participants because of the potential impact of these variables on information sharing. Hence, in this study, we also controlled for the gender (gender was coded as a dummy variable, 0 for women and 1 for men), age, work experience and education level of respondents.

\subsection{Common Method Bias Test}

When data are collected from the same respondents there might be common method bias issue. Therefore, to reduce common method bias, in our study we took into account the recommendations of Podsakoff et al. [42]. As noted earlier, in the cover letter of the survey forms, we assured the participants of the anonymity of their responses. Moreover, we utilized psychological separation by interspersing all the constructs of our study to decrease the respondents' perceptions of any direct connections between variables.

We followed the suggestion of Podsakoff et al. [42] and conducted Harman's one-factor test to evaluate the common method bias effect. Exploratory factor analysis was conducted by inserting all continuous variables. According to the principles of Harman's one-factor test, either a general factor will indicate the majority of the covariance or a single factor will emerge in the result. The findings indicate that there was no general factor that represented 
the majority of the variance, and no single factor emerged. Four factors were revealed from factor analysis, and the largest factor explained 23.094 percent of the variance.

Moreover, we examined the common method bias effect by conducting confirmatory factor analysis. In assessing confirmatory factor analysis, all items were included in a single factor. The findings revealed a poor model for a single factor. Comparative fit index $(\mathrm{CFI})=0.317$; Tucker Lewis index $(\mathrm{TLI})=0.287$; goodness-of-fit index $(\mathrm{GFI})=0.298$; the root mean square error of approximation $($ RMSEA $)=0.173)$.

\section{Results}

We used AMOS 21 to examine the measurement model and the validity of the hypotheses. To evaluate the model fit, previous studies [43] recommended assessing $\chi^{2}$-test goodness-of-fit indices, including CFI, GFI, adjusted goodness-of-fit index (AGFI), root mean square residual (RMR), RMSEA and standardized root mean square residual (SRMR). Thus, in our study, we measured overall model fit by $\left(\chi^{2}\right)$ CFI, GFI, AGFI, RMR, RMSEA and SRMR. CFI and GFI values higher than 0.90 and RMSEA and SRMR values lower than 0.60 and 0.05 indicate reasonable model fit. In our study, all goodness-of-fit indices $\left(\chi^{2}=362.932 ; \chi^{2} / \mathrm{df}=1.334 ; \mathrm{CFI}=0.990 ; \mathrm{GFI}=0.938 ; \mathrm{AGFI}=0.920 ; \mathrm{RMR}=0.069\right.$; RMSEA $=0.028 ;$ SRMR $=0.0337$ ) indicated a good fit to the data.

We assessed construct validity by evaluating discriminant and convergent validity. Convergent validity is the degree to which the items of the constructs that are supposed to be associated are in fact related [44]. Convergent validity was examined by assessing the factor loadings and composite reliability. The findings indicated that the factor loadings and composite reliabilities were higher than the required thresholds of 0.60 and 0.80 , respectively [45]. Hence, our model met the criteria for convergent validity.

Discriminant validity is the degree to which the measures of distinct latent constructs are different from those of other constructs [44]. To examine the discriminant validity, we assessed the average variance extracted (AVE). When the AVE values for each construct exceed 0.5 and the squared correlation between the same construct and other constructs, discriminant validity can be demonstrated [44]. The results revealed that the AVE values of the variables were higher than the threshold and the squared correlations between the constructs and the other variables. Thus, the measures indicated discriminant validity (Table 1).

Table 1. Means, standard deviations and bivariate correlations for variables.

\begin{tabular}{cccccccccc}
\hline & Variables & Mean & SD & AVE & $\mathbf{1}$ & $\mathbf{2}$ & $\mathbf{3}$ & $\mathbf{4}$ \\
\hline 1 & Abusive supervision & 3.12 & 1.14 & 0.632 & 1 & & & & \\
2 & Ineffectual silence & 2.96 & 1.41 & 0.849 & $0.108^{*}$ & 1 & & \\
3 & Defensive silence & 2.91 & 1.26 & 0.755 & $0.289^{* *}$ & $0.179 * *$ & 1 & \\
4 & Self-efficacy & 2.77 & 1.51 & 0.846 & $-0.239^{* *}$ & $-0.372^{* *}$ & -0.015 & 1 & \\
5 & Fear & 3.17 & 1.32 & 0.753 & $0.128^{* *}$ & 0.021 & $0.177^{* *}$ & 0.028 & 1 \\
\hline
\end{tabular}

Note: ${ }^{*} p<0.05 ;{ }^{* *} p<0.01$.

Table 1 presents the standard deviations, means, AVEs and correlations among the constructs. The results demonstrate that abusive supervision is positively correlated with ineffectual silence $(r=0.108, p<0.05)$, defensive silence $(r=0.289, p<0.01)$ and fear $(r=0.128, p<0.01)$ and negatively correlated with self-efficacy $(r=-0.239, p<0.01)$.

To assess the validity of the suggested hypotheses, we ran regression analysis. The findings suggest that abusive supervision is positively related to ineffectual silence ( $\beta=0.131$, $p<0.05)$. Thus, $\mathrm{H} 1$ is supported. Moreover, the regression analysis revealed that abusive supervision is positively associated with defensive silence $(\beta=0.316, p<0.01)$. Therefore, $\mathrm{H} 3$ is also supported. In $\mathrm{H} 2$, we hypothesized that self-efficacy moderates the relationship between abusive supervision and ineffectual silence. The results from hierarchical moderated regression analyses demonstrate that self-efficacy moderates the link between abusive supervision and ineffectual silence $(\beta=-0.237, p<0.01)$. Hence, $\mathrm{H} 2$ is empirically 
supported. Furthermore, the findings reveal that fear moderates the link between abusive supervision and defensive silence $(\beta=0.259, p<0.01$ ). Therefore, $\mathrm{H} 4$ is also supported (see Table 2).

Table 2. Results of hierarchical moderated regression analyses.

\begin{tabular}{|c|c|c|c|c|c|c|c|c|}
\hline & \multicolumn{3}{|c|}{ Ineffectual Silence } & \multicolumn{5}{|c|}{ Defensive Silence } \\
\hline & Model 1 & Model 2 & Model 3 & Model 4 & Model 1 & Model 2 & Model 3 & Model 4 \\
\hline \multicolumn{9}{|l|}{ Step 1: Control Variables } \\
\hline Age & 0.073 & 0.080 & 0.081 & 0.054 & 0.028 & 0.044 & 0.058 & 0.045 \\
\hline Gender & -0.063 & -0.065 & -0.075 & -0.036 & -0.061 & -0.066 & -0.060 & -0.085 \\
\hline Work experience & 0.190 & 0.181 & 0.125 & 0.121 & 0.085 & 0.065 & 0.068 & 0.052 \\
\hline Education level & 0.150 & 0.135 & 0.169 & 0.133 & 0.114 & 0.077 & 0.074 & 0.063 \\
\hline \multicolumn{9}{|l|}{ Step 2: Main effects } \\
\hline Abusive Supervision & & 0.131 * & 0.025 & 0.029 & & $0.316^{* *}$ & $0.296^{* *}$ & $0.312 * *$ \\
\hline \multicolumn{9}{|l|}{ Step 3: Main effects } \\
\hline Self-efficacy & & & $-0.338^{* *}$ & $-0.349 * *$ & & & & \\
\hline Fear & & & & & & & 0.138 * & $0.136^{*}$ \\
\hline \multicolumn{9}{|l|}{ Step 4: Interaction } \\
\hline Ab.Sup X Self-efficacy & & & & $-0.237^{* *}$ & & & & \\
\hline Ab.Sup X Fear & & & & & & & & $0.259 * *$ \\
\hline$R^{2}$ & 0.015 & 0.026 & 0.147 & 0.224 & 0.004 & 0.087 & 0.108 & 0.205 \\
\hline Adjusted $R^{2}$ & 0.008 & 0.017 & 0.137 & 0.212 & 0.003 & 0.078 & 0.097 & 0.194 \\
\hline \multicolumn{9}{|l|}{ Change in $R^{2}$} \\
\hline $\mathrm{F}$ & 2.119 & 2.763 & 14.103 & 19.530 & 0.577 & 9.762 & 9.882 & 17.534 \\
\hline
\end{tabular}

To interpret the form of the interaction, we plotted the simple slopes for the links between abusive supervision and two forms of silence, ineffectual and defensive. When individuals have a higher level of self-efficacy, abusive supervision is related to a lower level of ineffectual silence $(\beta=-0.329, p<0.05)$. When individuals have a lower level of self-efficacy, simple slopes indicate that abusive supervision is related to a higher level of ineffectual silence $(\beta=0.390, p<0.01)$ (see Figure 2$)$.

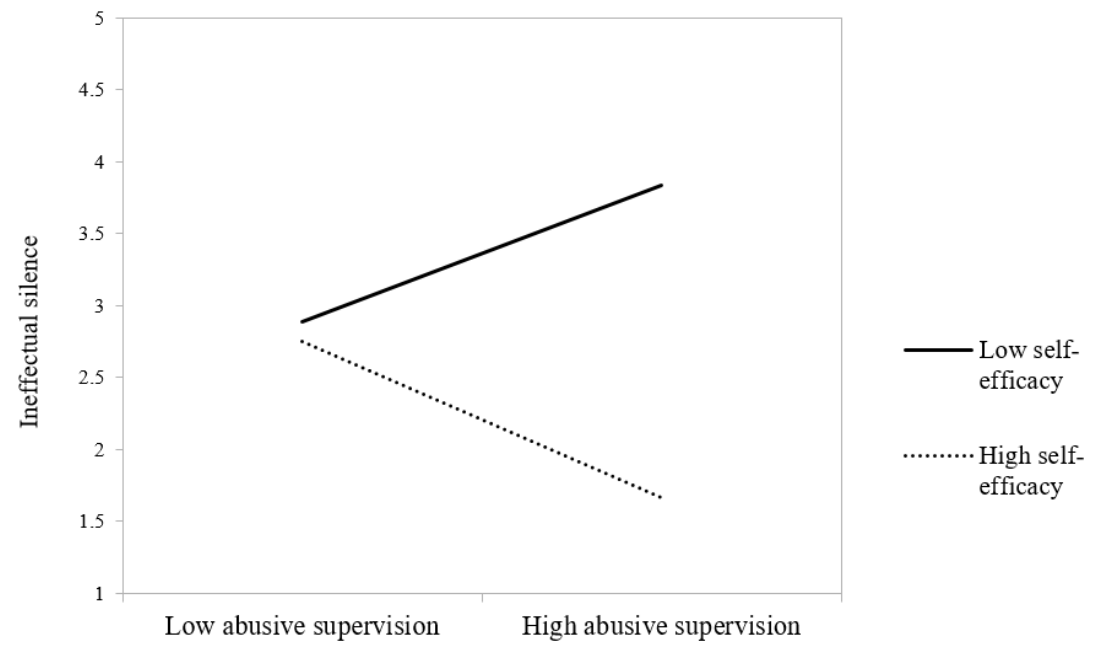

Figure 2. Moderating effect of self-efficacy on the relationship between abusive supervision and ineffectual silence.

Moreover, simple slope analysis demonstrates that when individuals have a higher level of fear, abusive supervision is related to a higher level of defensive silence $(\beta=0.656$, $p<0.01$ ) (see Figure 3). 


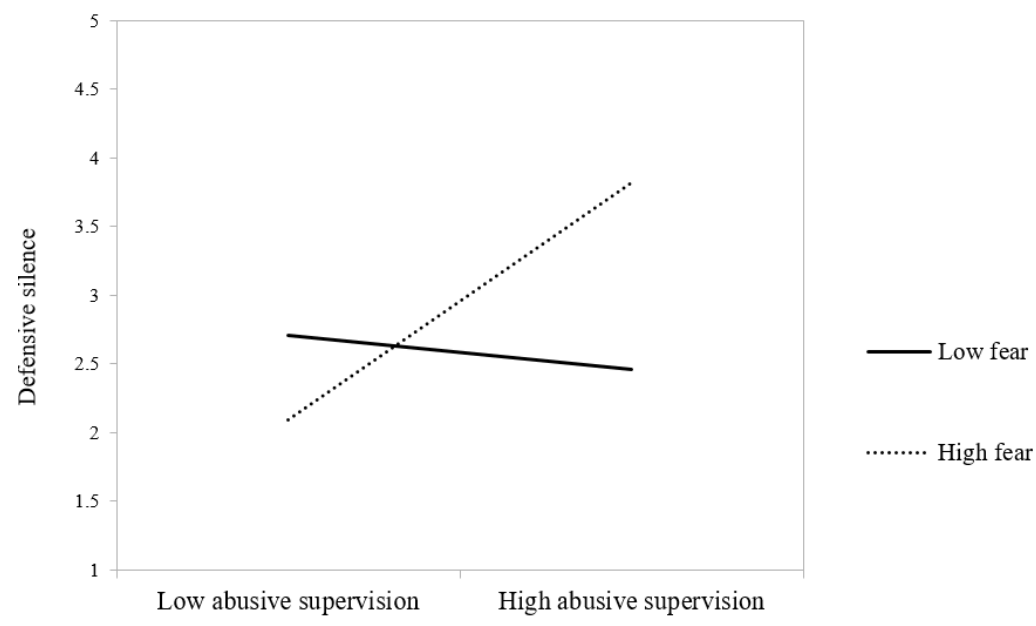

Figure 3. Moderating effect of fear on the relationship between abusive supervision and defensive silence.

Furthermore, the findings suggest that control variables such as the gender, age, work experience and education level of employees do not impact their silence.

\section{Discussion}

\subsection{Discussion}

Our study investigates the associations between abusive supervision and two forms of silence (i.e., ineffectual and defensive), examines the contingent role of self-efficacy on the link between abusive supervision and ineffectual silence and studies the boundary condition role of fear on the link between abusive supervision and defensive silence.

The results suggest that abusive supervision is negatively related to ineffectual silence. In other words, when supervisors mistreat individuals by being rude and yelling at them, employees tend to withhold ideas and recommendations based on the idea that efforts to change the situation by speaking up are useless because their voice may not be considered seriously by the managers. This finding is consistent with the statements of Wang and Jiang [18]. Moreover, the findings indicate that abusive supervision is positively associated with defensive silence. Specifically, when supervisors express their anger at individuals when they are mad for another reason, individuals feel reluctant to speak up and suggest ideas for change based on fear. This finding is in line with the study of [5] who reported the positive link between abusive supervision and fear-based silence.

Further, hierarchical regression analysis suggest that self-efficacy moderates the link between abusive supervision and ineffectual silence. That is, despite the mistreatment of superiors, individuals who have a higher level of confidence in completing tasks successfully are less likely to remain silent based on the belief that speaking up does not make a difference. We believe that individuals who have higher level of self-efficacy perceive the successful completion of their jobs as a reward and achievement and therefore, they tend to use approach behavior which eventually makes them to share their concerns to attain their goals.

On the contrary, individuals working under abusive supervision who have lower level of self-efficacy, are more likely to refrain themselves from information sharing based on the perception that sharing information does not make any change. Furthermore, the results reveal that fear moderates the relationship between abusive supervision and defensive silence. In other words, when superiors have abusive behavior individuals with fear tend to remain silent based on self-defense. These findings support the perceptions of the biopsychology theory of personality [23].

\subsection{Theoretical Contribution}

Our study extends the literature in several ways. First, previous research mainly investigated the unitary construct of silence and one of the dimensions of the multidimensional 
construct of silence, defensive silence. We believe that in addition to threat perceptions, abusive supervisors can give the perception of unfairness with mistreatment [28], which causes individuals' reluctance to make efforts toward change in organizations because of their belief that their suggestions are not considered seriously [10]. Hence, our work goes one step further by suggesting that as a response to abusive supervisors, individuals may also withhold information based on their inability to affect the environment with their voice. Thus, our study responds to Tepper's [7] call by investigating individuals' response to abusive supervision, specifically by examining ineffectual silence as a response to the abusive behavior of supervisors. The findings of our study indicate that abusive supervision is positively related to ineffectual silence. Our work extends the literature by providing a richer understanding of the associations between abusive supervision and ineffectual silence. More specifically, this finding enables the management of organizations to understand that when supervisors are abusive, members of organizations not only withhold information based on self-protection but also may restrain themselves from initiating change in workplace because of their perception that speaking up does not change the environment. Understanding individuals' motives for withholding information helps practitioners target the core reasons for silence in their attempt to reduce it.

Second, depending on their capabilities to handle the situation, individuals' responses to abusive supervision can also differ [22]. Despite the number of studies on abusive supervision and silence, there is still a lack of a cogent theoretical framework that indicates the situations when abusive supervisors foster employee silence and when individuals have reduced silence with abusive supervisors because previous research on abusive supervision and silence did not take into account the boundary condition roles of individual factors in response to abusive supervisors. Thus, to address the gaps in the literature, we invoked the biopsychology theory of personality to apply a fresh perspective by assessing the contingent role of self-efficacy in the link between abusive supervision and ineffectual silence. Our study suggests that not all individuals are vulnerable to the abusive behavior of supervisors. Specifically, the findings indicate that abusive supervision indeed leads to ineffectual silence only if the subordinates have low self-efficacy. In fact, employees with high self-efficacy are shown to be able to persevere the abusive supervision due to their belief in their capability to successfully complete tasks and achieve a reward in workplace by taking approach behavior and avoiding silence. Our findings contribute to the literature by showing the critical role of self-efficacy in impacting the silence of employees working with abusive supervisors. Third, although much is known about the relationship between abusive supervision and defensive silence, we have less understanding when the links between abusive supervision and defensive silence become stronger. In other words, the question regarding when individuals have a higher level of defensive silence under abusive supervision remains unanswered. Hence, by drawing from the biopsychology theory of personality and empirically examining this perspective, our study suggests that under abusive supervision, fearful individuals use avoidance behavior by engaging in defensive silence because of their expectation of threat from their superiors. Hence, the higher the level of fear, the higher the level of defensive silence will be when supervisors are abusive.

\subsection{Practical Implications}

Based on the findings, our study suggests practical implications to mitigate silence in business organizations.

Our findings reveal that abusive supervision is positively associated with ineffectual and defensive silence. Therefore, we recommend the use of appropriate punishment systems to mitigate the misconduct of supervisors [46]. In other words, organizations should give clear guidelines to employees about punishment for disobeying organizational rules and policies. This legalized punishment can reduce other illegal activities of superiors and give employees a sense of safety and fairness. Additionally, we recommend that organizations solicit individuals' opinions in the decision-making process [47] to reduce ineffectual silence. When managers solicit the opinions of employees, individuals perceive 
that their suggestions can be taken seriously by management, and with this perception, members of organizations are less likely to practice ineffectual silence. Moreover, the findings indicate that self-efficacy weakens the links between abusive supervision and ineffectual silence. Thus, we suggest that managers design a training program that enables employees to master the skills and knowledge to complete assigned tasks well, which ultimately enhances self-efficacy [25]. Furthermore, we recommend that management implement mastery modeling and supportive supervisory practices to enhance employees' self-efficacy [48]. The results also suggest that an individual's fear strengthens the link between abusive supervision and defensive silence. Managers of organizations can create an open and safe climate to increase employees' voice because psychological safety and an open climate mitigate individuals' fear, which is associated with defensive silence [35]. Organizations can also establish communication channels to foster communication between management and subordinates. Establishing communication channels reduces individuals ${ }^{\prime}$ fear because it shows the openness of management to ideas and recommendations.

\subsection{Limitations and Future Research Directions}

Even though our study contributes the literature, our work has several limitations and provides recommendations for future studies. First, our work assesses the relationships between abusive supervision and two forms of silence, ineffectual and defensive. We recommend that future research take into account other forms of silence [27] in examining the link between abusive supervision and silence. Second, to assess the research model of our study, we collected data from highly-skilled employees of manufacturing companies. White-collar and blue-collar workers differ in terms of expressing their full potential. Therefore, to provide more knowledge and different perspectives on the links between abusive supervision and different forms of silence, we recommend that future research study this dynamic among blue-collar workers. Third, in this study, we investigated only the antecedents of ineffectual and defensive silence. There is very little knowledge on the outcomes of silence that is generated by abusive supervision. Hence, we recommend that scholars examine the associations among abusive supervision, ineffectual and defensive silence and their outcomes. Fourth, the current research used a cross-sectional design. Thus, we suggest that scholars use longitudinal studies because the associations between abusive supervision and ineffectual and defensive silence can develop over time. Fifth, another limitation of our work might be the generalizability of the findings because the data for this study was collected in a single country, the Republic of Korea. Therefore, to attain more generalizable results, this type of research should be studied in several countries.

Author Contributions: Conceptualization, A.T.D.; methodology, A.T.D. and O.S.A.; formal analysis, A.K.u.F. and W.S.; investigation, A.K.u.F.; resources, O.S.A.; data curation, A.K.u.F.; writing—original draft preparation, O.S.A.; writing-review and editing, W.S.; supervision, A.T.D.; project administration, A.T.D.; funding acquisition, A.T.D. All authors have read and agreed to the published version of the manuscript.

Funding: This work was supported by Ministry of Education of the Republic of Korea and the National Research Foundation of Korea under Grant NRF-2019S1A5A8037600.

Institutional Review Board Statement: Akfa University Institutional Review Board issued the waivers for the research in this paper because it involves no more than minimal risk to the privacy of survey participants.

Informed Consent Statement: Not applicable.

Data Availability Statement: Not applicable.

Conflicts of Interest: The authors declare no conflict of interest.

\section{References}

1. Dedahanov, A.T.; Rhee, C.; Yoon, J. Organizational structure and innovation performance: Is employee innovative behavior a missing link? Career Dev. Int. 2017, 22, 334-350. [CrossRef] 
2. Morrison, E.W.; See, K.E.; Pan, C. An approach-inhibition model of employee silence: The joint effects of personal sense of power and target openness. Pers. Psychol. 2015, 68, 547-580. [CrossRef]

3. Greenberg, J.; Edwards, M.S. Voice and Silence in Organizations; Emerald: Bingley, UK, 2009.

4. Park, J.H.; Carter, M.Z.; DeFrank, R.S.; Deng, Q. Abusive supervision, psychological distress, and silence: The effects of gender dissimilarity between supervisors and subordinates. J. Bus. Ethics 2018, 153, 775-792. [CrossRef]

5. Kiewitz, C.; Restubog, S.L.D.; Shoss, M.K.; Garcia, P.R.J.M.; Tang, R.L. Suffering in silence: Investigating the role of fear in the relationship between abusive supervision and defensive silence. J. Appl. Psychol. 2016, 101, 731-742. [CrossRef]

6. Lam, L.W.; Xu, A.J. Power imbalance and employee silence: The role of abusive leadership, power distance orientation, and perceived organisational politics. Appl. Psychol. 2019, 68, 513-546. [CrossRef]

7. Tepper, B.J. Abusive supervision in work organizations: Review, synthesis, and research agenda. J. Manag. 2007, 33, 261-289. [CrossRef]

8. Thau, S.; Bennett, R.J.; Mitchell, M.S.; Marrs, M.B. How management style moderates the relationship between abusive supervision and workplace deviance: An uncertainty management theory perspective. Organ. Behav. Hum. Decis. Processes 2009, 108, 79-92. [CrossRef]

9. Brislin, R. Understanding Culture's Influence on Behavior; Harcourt Brace Jovanovich: Fort Worth, TX, USA, 1993.

10. Pinder, C.C.; Harlos, K.P. Employee silence: Quiescence and acquiescence as responses to perceived injustice. In Research in Personnel and Human Resources Management; Rowland, K.M., Ferris, G.R., Eds.; JAI Press: New York, NY, USA, 2001; pp. 331-369.

11. Van Dyne, L.; Ang, S.; Botero, I. Conceptualizing employee silence and employee voice as multidimensional constructs. J. Manag. Stud. 2003, 40, 1360-1392.

12. Jain, A.K.; Srivastava, S.; Cooper, C. A study on the relationship of abusive supervision and fear based silence in India the mediating role of dimensions of emotional intelligence. Curr. Psychol. 2021, 40,1-16. [CrossRef]

13. Wang, C.C.; Hsieh, H.H.; Wang, Y.D. Abusive supervision and employee engagement and satisfaction: The mediating role of employee silence. Pers. Rev. 2020, 49, 1845-1858. [CrossRef]

14. Al-Hawari, M.A.; Bani-Melhem, S.; Quratulain, S. Abusive supervision and frontline employees' attitudinal outcomes: The multilevel effects of customer orientation. Int. J. Contemp. Hosp. Manag. 2020, 32, 1109-1129. [CrossRef]

15. Ai-Hua, H.; Yang, L.; Guo-Tao, G. Abusive supervision and employee silence: The mediating effect of perceptions of organizational politics and the moderating effect of LMX. J. Glob. Bus. Insights 2018, 3, 19-37. [CrossRef]

16. Xu, Q.; Zhao, Y.; Xi, M.; Li, F. Abusive supervision, high-performance work systems, and subordinate silence. Pers. Rev. 2020, 49, 1637-1653. [CrossRef]

17. Huang, J.; Guo, G.; Tang, D.; Liu, T.; Tan, L. An Eye for an Eye? Third Parties' Silence Reactions to Peer Abusive Supervision: The Mediating Role of Workplace Anxiety, and the Moderating Role of Core Self-Evaluation. Int. J. Environ. Res. Public Health 2019, 16, 5027. [CrossRef]

18. Wang, R.J. How abusive supervisors influence employees' voice and silence: The effects of interactional justice and organizational attribution. J. Soc. Psychol. 2015, 155, 204-220. [CrossRef]

19. Xu, A.J.; Loi, R.; Lam, L.W. The bad boss takes it all: How abusive supervision and leader-member exchange interact to influence employee silence. Leadersh. Q. 2015, 26, 763-774. [CrossRef]

20. Pangestu, R.N.; Wulansari, N.A. The effect of abusive supervision on employee silence using emotional exhaustion and organizational justice as a mediation variable. Manag. Anal. J. 2019, 8, 58-67.

21. Rafferty, A.E.; Restubog, S.L.D. The influence of abusive supervisors on followers' organizational citizenship behaviours: The hidden costs of abusive supervision. Br. J. Manag. 2011, 22, 270-285. [CrossRef]

22. Chi, S.C.S.; Liang, S.G. When do subordinates' emotion-regulation strategies matter? Abusive supervision, subordinates' emotional exhaustion, and work withdrawal. Leadersh. Q. 2013, 24, 125-137. [CrossRef]

23. Gray, J.A. A Model for Personality. In A Model for Personality; Eysenck, H.J., Ed.; Springer: New York, NY, USA, 1981; pp. 246-276.

24. Gibsons, D.E.; Weingart, L.R. Can I do it? Will I try? Personal efficacy, assigned goals, and performance norms as motivators of individual performance. J. Appl. Soc. Psychol. 2001, 31, 624-648. [CrossRef]

25. Dedahanov, A.T.; Rhee, C.; Gapurjanova, N. Job autonomy and employee voice: Is work-related self-efficacy a missing link? Manag. Decis. 2019, 57, 2401-2413. [CrossRef]

26. Dedahanov, A.T.; Rhee, J. Examining the relationships among trust, silence and organizational commitment. Manag. Decis. 2015, 53, 1843-1857. [CrossRef]

27. Brinsfield, C.T. Employee silence motives: Investigation of dimensionality and development of measures. J. Organ. Behav. 2013, 34, 671-697. [CrossRef]

28. Tepper, B.J. Consequences of abusive supervision. Acad. Manag. J. 2000, 43, 178-190.

29. Boroff, K.E.; Lewin, D. Loyalty, voice, and intent to exit a union firm: A conceptual and empirical analysis. Ind. Labor Relat. Rev. 1997, 51, 50-63. [CrossRef]

30. Demiralay, T.; Lorcu, F. Examining Organizational Silence on Doctors with Structural Equation Modeling. Int. J. Bus. Soc. Sci. 2015, 6, 37-49.

31. Whiteside, D.B.; Barclay, L.J. Echoes of silence: Employee silence as a mediator between overall justice and employee outcomes. J. Bus. Ethics 2013, 116, 251-266. [CrossRef] 
32. Bandura, A. Self-efficacy. In Encyclopedia of Human Behavior, 4th ed.; Ramachaudran, V.S., Ed.; Academic Press: New York, NY, USA, 1997; pp. 71-81.

33. Walumba, F.O.; Wang, P.; Wang, H.; Schaubroeck, J.; Avolio, B.J. Psychological processes linking authentic leadership to follower behaviors. Leadersh. Q. 2010, 21, 901-914. [CrossRef]

34. Schlenker, B.R.; Weigold, M.F. Self-identification and accountability. In Impression Management in the Organization Erlbaum; Giacalone, R.A., Rosenfeld, P., Eds.; Psychology Press: Hillsdale, NJ, USA, 1989; pp. 21-43.

35. Guo, L.; Decoster, S.; Babalola, M.T.; De Schutter, L.; Garba, O.A.; Riisla, K. Authoritarian leadership and employee creativity: The moderating role of psychological capital and the mediating role of fear and defensive silence. J. Bus. Res. 2018, 92, 219-230. [CrossRef]

36. Milliken, F.J.; Morrison, E.W.; Hewlin, P.F. An exploratory study of employee silence: Issues that employees don't communicate upward and why. J. Manag. Stud. 2003, 40, 1453-1473. [CrossRef]

37. Russel, B. Social Research Methods: Qualitative and Quantitative Approaches; Sage: Thousand Oaks, CA, USA, 2000.

38. Spreitzer, G.M. Psychological empowerment in the workplace: Dimensions, measurement, and validation. Acad. Manag. J. 1995, 38, 1442-1465.

39. Watson, D.; Clark, L.A. The PANAS-X: Manual for the Positive and Negative Affect Schedule-Expanded Form. 1999 Available online: https://iro.uiowa.edu/esploro/outputs/other/The-PANAS-X-Manual-for-the-Positive/9983557488402771 \#details (accessed on 5 October 2019).

40. Chan, S.C. Paternalistic leadership and employee voice: Does information sharing matter? Hum. Relat. 2014, 67, 667-693. [CrossRef]

41. Dedahanov, A.T.; Lee, D.; Rhee, J.; Yusupov, S. An examination of the associations among cultural dimensions, relational silence and stress. Pers. Rev. 2016, 45, 593-604. [CrossRef]

42. Podsakoff, P.M.; MacKenzie, S.B.; Lee, J.; Podsakoff, N.P. Common method biases in behavioral research: A critical review of the literature and recommended remedies. J. Appl. Psychol. 2003, 88, 879-903. [CrossRef]

43. Kline, R.B. Principles and Practice of Structural Equation Modeling, 3rd ed.; Guilford Press: New York, NY, USA, 2010.

44. Hair, J.R.; Black, W.C.; Babin, B.J.; Anderson, R.E. Multivariate Data Analysis: A Global Perspective, 7th ed.; Pearson Prentice-Hall: Upper Saddle River, NJ, USA, 2010.

45. Fornell, C.; Larcker, D.F. Evaluating structural equation models with unobservable variables and measurement error. J. Mark. Res. 1981, 18, 39-50. [CrossRef]

46. Robinson, S.L.; O'Leary-Kelly, A.M. Monkey see, monkey do: The influence of work groups on the antisocial behavior of employees. Acad. Manag. J. 1998, 41, 658-672.

47. Dedahanov, A.T.; Lee, D.H.; Rhee, J.; Yoon, J. Entrepreneur's paternalistic leadership style and creativity: The mediating role of employee voice. Manag. Decis. 2016, 54, 2310-2324. [CrossRef]

48. Nauta, M.M.; Liu, C.; Li, C. A cross-national examination of self-efficacy as a moderator of autonomy/job strain relationships. Appl. Psychol. 2010, 59, 159-179. [CrossRef] 